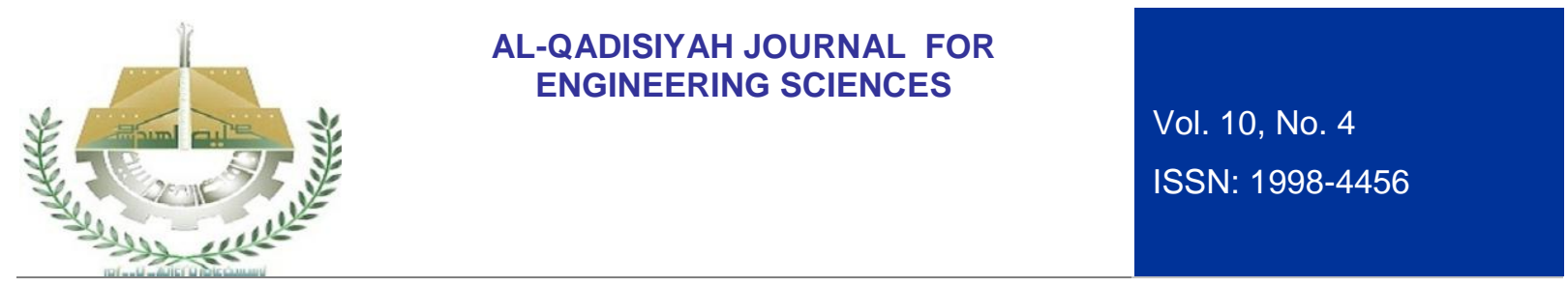

\title{
EVALUATION OF THE EFFECT OF LENGTH ON THE PERFORMANCE OF RECTANGULAR TO RECTANGULAR WAVEGUIDE TAPER
}

\author{
Hasan F. Khazaal, \\ Wasit University, College of Engeneering, Electrical Engineering, Iraq. \\ E-mail: hf1964@yahoo.com \\ Haider Th. Salim ALRikabi, \\ Wasit University, College of Engeneering, Electrical Engineering, Iraq. \\ E-mail: haiderelectrical@gmail.com \\ Mansour S. Farhan, \\ Wasit University, College of Engeneering, Electrical Engeneering, Iraq. \\ E-mail: mansur545@yahoo.com
}

Received on 14 September 2017 Accepted on 31 October 2017 Published on 20 February 2018 DOI: $10.30772 /$ qjes.v10i4.503

\begin{abstract}
RF Waveguide taper have a significant role in radar or communication systems through the use of it for joining two waveguides that have different cross sections, and this difference may be in dimensions of cross section or in the shape of it. the tapering may be from rectangular to rectangular waveguide (i.e. each waveguide operating at a certain frequency), or transition from rectangular to circular or elliptical waveguide. In this paper; two rectangular to rectangular waveguide tapers have been fabricated to join waveguide operating at $C$ band frequencies with another one operating at $X$ band frequencies. The fabricated tapers have the same shape but differ in length $(8 \mathrm{~cm}$, and $16 \mathrm{~cm})$ in order to measure the effect of length on the most important parameters that have an effect on the performance of the taper, like voltage standing wave ratio "VSWR", return losses, and input resistance. Many tests have been done using two - port network analyzer. The results of the tests indicate that there is no effect on the performance of the waveguide taper although there is an extra $8 \mathrm{~cm}$ in length.
\end{abstract}

Keywords: waveguide, radio frequency, VSWR, return losses, input resistance.

\section{INTRODUCTION}

This RF waveguide transition or tapers are used to connect waveguide components with different cross sectional sizes and shapes. There are many kinds of waveguide tapers, like rectangular-to-rectangular of radio frequency waveguide transition adapters which designed to connect one rectangular waveguide to 


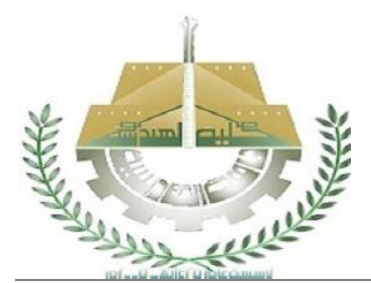

\section{AL-QADISIYAH JOURNAL FOR ENGINEERING SCIENCES}

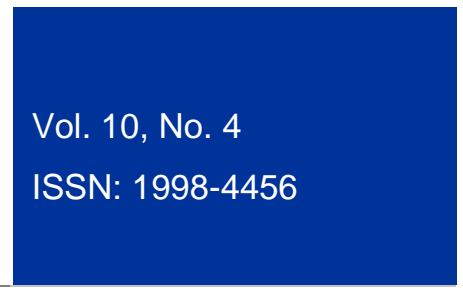

another rectangular waveguide but in different cross section size. Similarly, circular-to-circular adapters are used to connect one circular waveguide to another circular waveguide. Circular-to-rectangular waveguides that change a circular waveguide section to rectangular waveguide section [1]. In a tapered section, the dimensions of waveguide vary smoothly and for this reason there are possibilities of providing a transition from one impedance level to another [2].

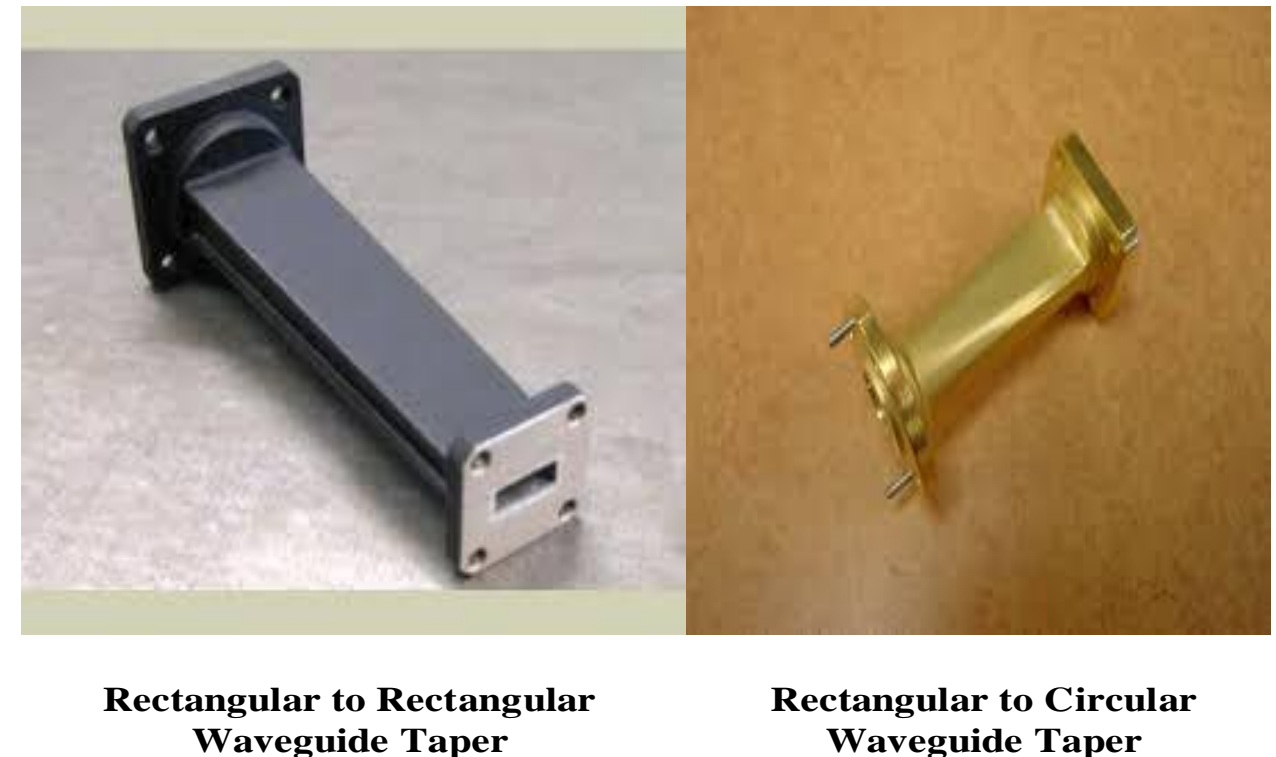

Figure 1: shows the types of waveguide taper and transition.

The aim of the research is to compare the performance of two waveguide tapers differ in length but have the same rectangular cross section of both corresponding ends. These tapers must be used to connect between waveguide operating at $\mathrm{C}-$ band frequencies into waveguide operating at $\mathrm{X}$-band frequencies. The comparison here covering the most significant parameters; voltage standing wave ratio, return losses, and input resistance, and impedance.

The paper is arranged as follows; Introduction, background, practical work and testing, results, discussion, and conclusions.

\section{BACKGROUND}

Article Rectangular to rectangular waveguide tapers used to make transition between two different waveguide cross sections in order to mitigate some technical problems in connection and / or to reduce the cost of using new waveguides in a whole system. The taper behaves like frequency transformer because the two connected waveguides operating at different frequency bands. Figure 2 show the types of rectangular to rectangular waveguide tapers with different flanges. 

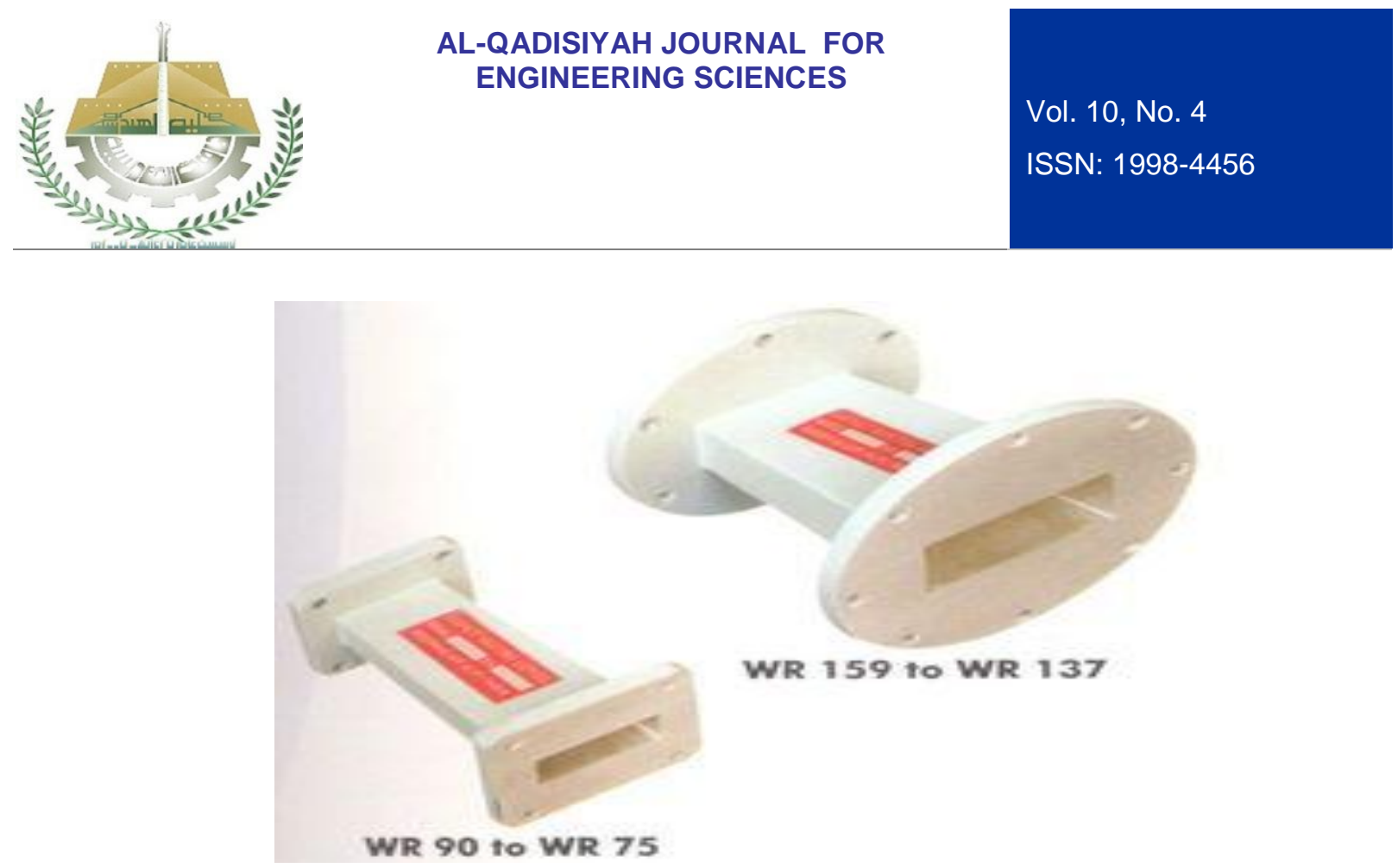

Figure 2: Types of rectangular to rectangular waveguide tapers [3].

In order to satisfy the aim of this work, the fabrication of two rectangular to rectangular waveguide tapers have been done. These tapers have difference in length but have the same cross section dimensions for corresponding ends, in order to check the effect of length on the most common characteristic, voltage standing wave ratio "VSWR", return losses, and input resistance.

The fabricated waveguide tapers are subjected to the following boundaries:

- VSWR of the tapers $\leq 2$.

- High return losses as possible.

- Input resistance near $50 \mathrm{Ohm}$.

Voltage standing wave proportion (VSWR) is a unit-less proportion extending from one to limitlessness. It communicates the measure of reflected vitality at the information or yield of the gadget. An estimation of one demonstrates that the majority of the vitality will go through, while some other esteem shows that a bit of the vitality will be reflected.

In media communications, return misfortune is the loss of influence in the signal returned/reflected by an irregularity in a transmission line or optical fiber. This intermittence can be mismatched with the ending load or with a device embedded in the line. It is typically communicated as a proportion in decibels $(\mathrm{dB})[4,5]$.

$$
R L(d B)=10 \log _{10} \frac{P_{i}}{P_{r}}
$$

where $R L(d B)$ is the return loss in $d B, P i$ is the incident power and $\operatorname{Pr}$ is the reflected power. reflection coefficient $(\Gamma)$ can be calculated as;

$$
\Gamma=\frac{\mathrm{V}_{\mathrm{r}}}{\mathrm{V}_{\mathrm{i}}}=\frac{\mathrm{Z}_{\mathrm{L}}-\mathrm{Z}_{\mathrm{S}}}{\mathrm{Z}_{\mathrm{L}}+\mathrm{Z}_{\mathrm{S}}}
$$

Where $\mathrm{V}_{\mathrm{r}}, \mathrm{V}_{\mathrm{i}}$ are the reflected and incident voltage respectively. And are the load and source impedance respectively. 


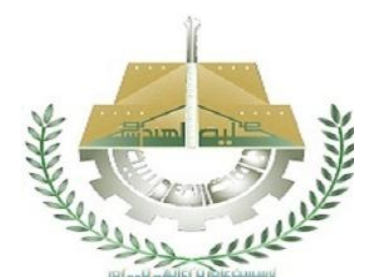

Return losses is related with reflection coefficient as shown in equation (2.3).

$$
R L(d B)=-20 \log _{10}|\Gamma|
$$

Return loss has a relation to "both standing wave proportion (SWR) and reflection coefficient $(\Gamma)$. Expanding return loss relates to bring down SWR. Return loss is a measure of how well gadgets or lines are coordinated. A match is great if the arrival misfortune is high. An exceptional yield misfortune is alluring and brings about a lower inclusion misfortune.

Return loss is utilized as a part of present day practice in inclination to VSWR in light of the fact that it has better determination for little estimations of reflected wave.

Properly, misfortune amounts, when expressed in decibels, ought to be certain numbers. In any case, return loss has generally been communicated as a negative number, and this tradition is still broadly found in the writing. The right meaning of return misfortune is the distinction in $\mathrm{dB}$ between the occurrence influence sent towards the Device Under Test (DUT) and the influence reflected, bringing about a positive sign":

Be that as it may, taking the proportion of reflected to episode control brings about a negative sign for return loss;

$$
\mathrm{RL}^{\prime}(\mathrm{dB})=10 \log _{10} \frac{\mathrm{P}_{\mathrm{r}}}{\mathrm{P}_{\mathrm{i}}}
$$

where $R L^{\prime}(d B)$ is the negative of $R L(d B)$.

Return loss with a positive sign is indistinguishable to the greatness of $\Gamma$ when expressed in decibels yet of inverse sign. That is, "return misfortune with a negative sign is all the more legitimately called reflection coefficient. The S-parameter S11 from two-port system hypothesis is every now and again likewise called return misfortune, yet is really equivalent to $\Gamma "$.

Caution is required while talking about expanding or diminishing return loss since these terms entirely have the inverse importance when return misfortune is characterized as a negative amount.

For this presented work it would be to get the value of VSWR and return losses according to the international standards.

\section{FABRICATION AND TESTING OF WAVEGUIDE TAPERS}

\subsection{FABRICATION OF WAVEGUIDE TAPER}

The practical work has been done by fabricating two of rectangular to rectangular waveguide tapers. The fabricated tapers were made from Aluminum sheet metals having thickness of $3 \mathrm{~mm}$. The sheet metal is processed by milling to the shapes and dimensions indicating in figures (3-7), to prepare taper's walls and the connections flanges. The shaped walls and flanges are assembled together to make the final products as shown in figures (8-9). 


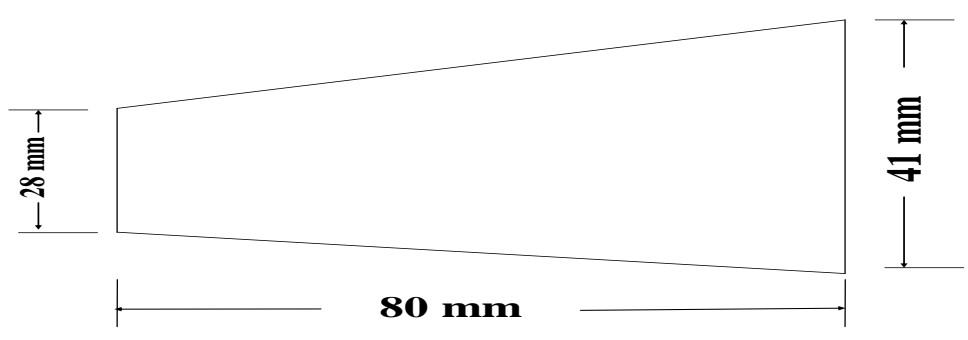

Figure 3: E- Plane side wall of short taper.

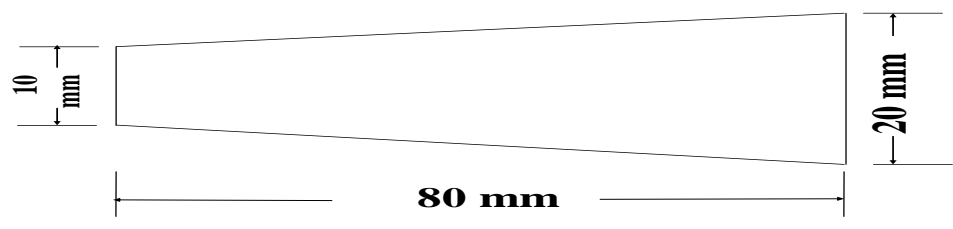

Figure 4: $\mathrm{H}$ - Plane side wall of short taper.

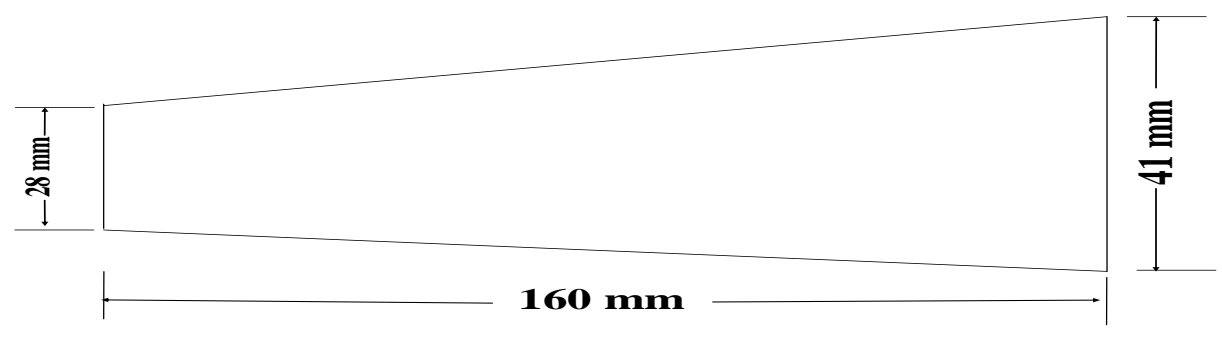

Figure 5: E- Plane side wall of long taper. 


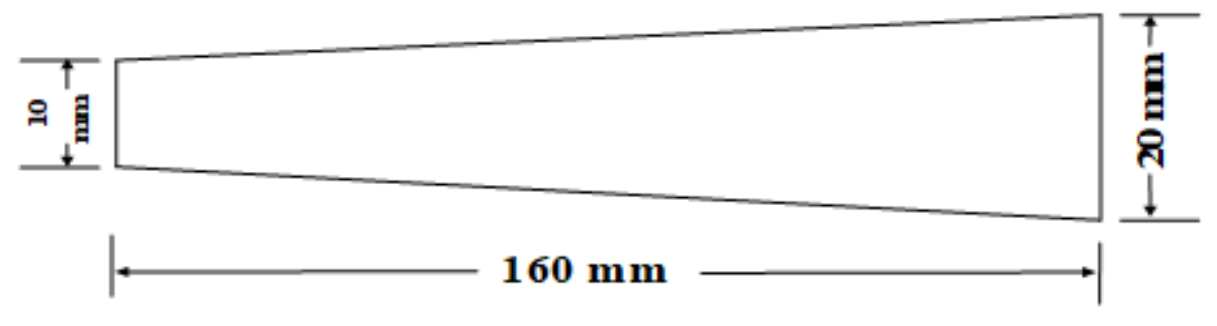

Figure 6: $\mathrm{H}$ - Plane side wall of long taper.

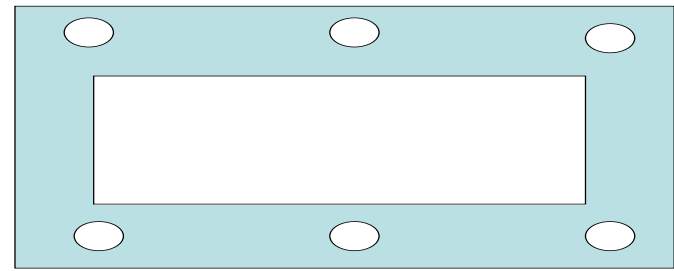

C-Band connection flange

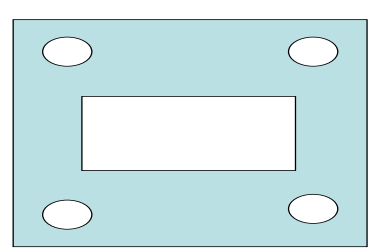

X-Band connection flange

Figure 7: Connection flanges.

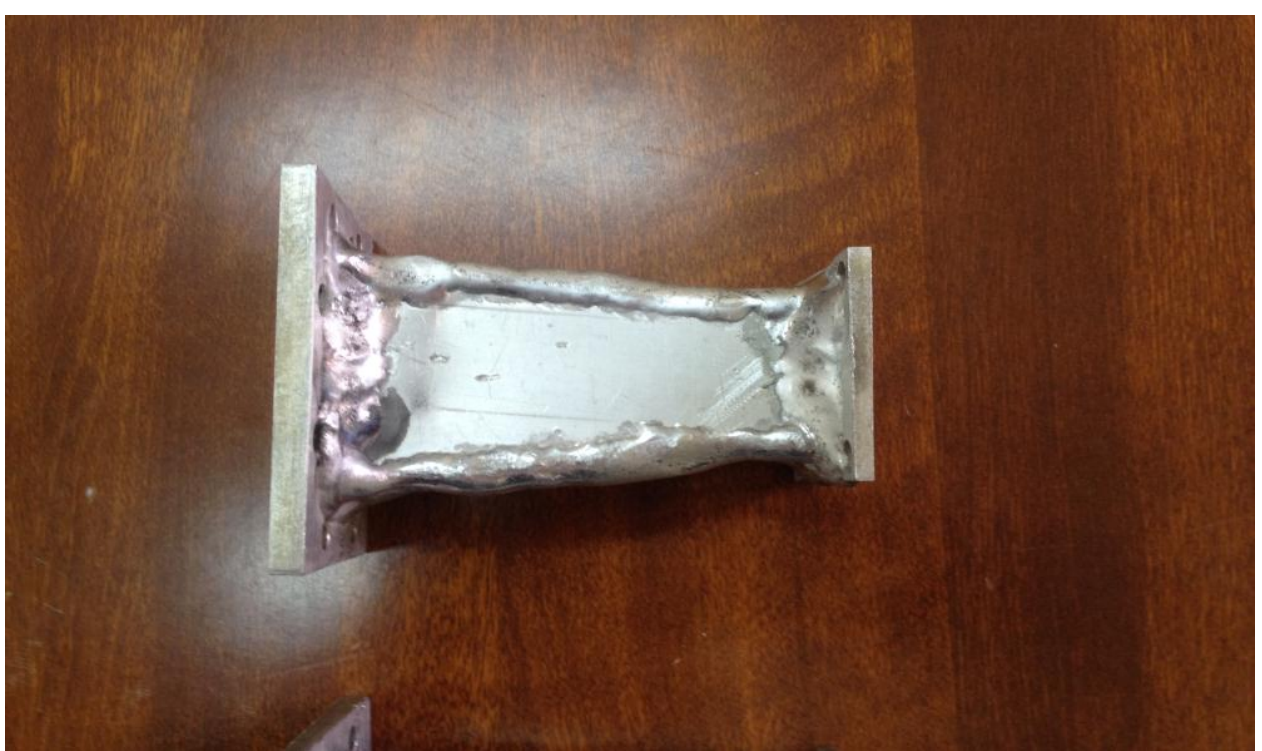

Figure 8: Assembled short waveguide taper. 

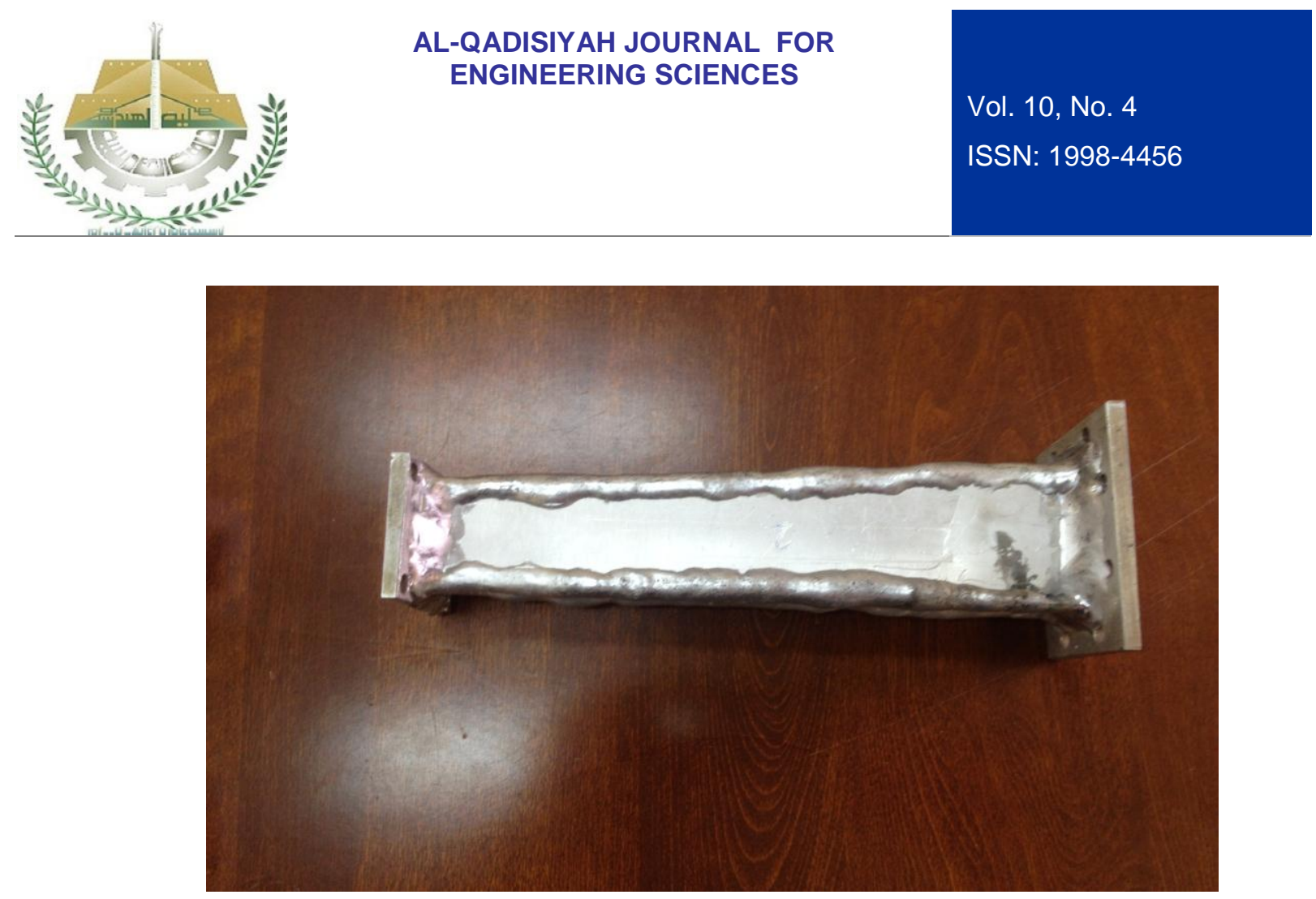

Figure 9: Assembled long waveguide taper.

\subsection{TESTING}

The fabricated tapers subjected to $(S)$ and $(Z)$ parameters tests to point out the values of reflection losses, input resistance and impedance, and VSWR of each taper, in order to compare the performance of them. The tests done by using two port network analyzer as shown in figure (10) . 2.3. authors

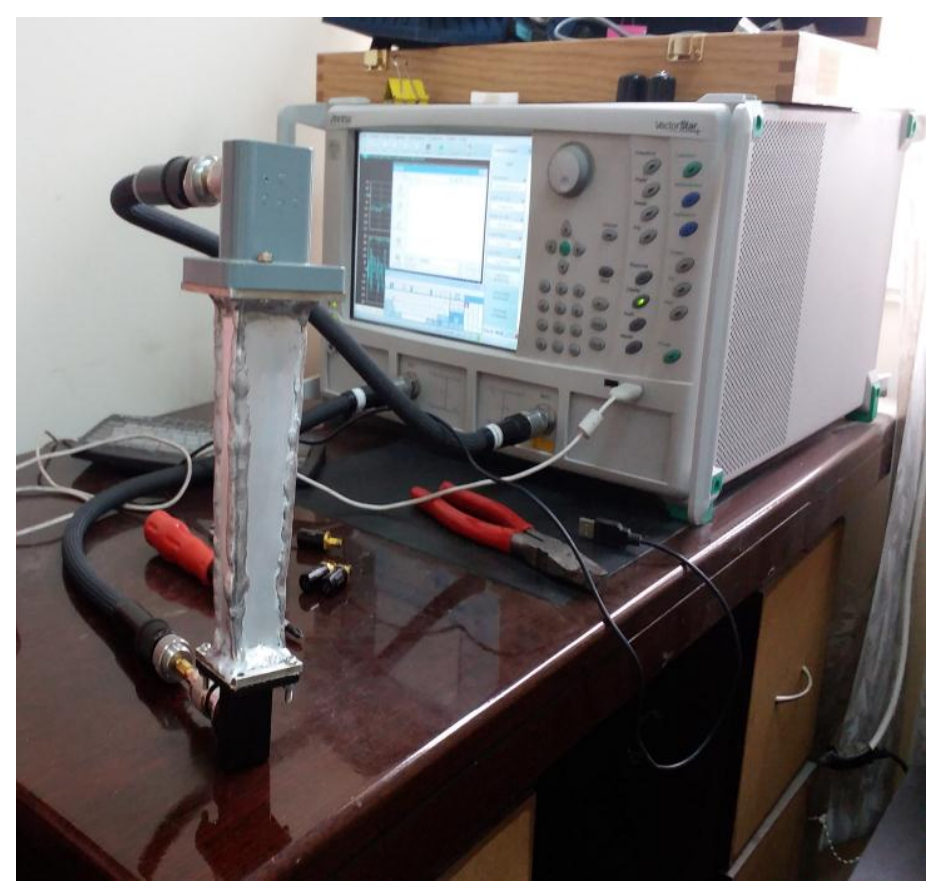

Figure 10: Waveguide taper test setup using two port network analyzer. 


\section{AL-QADISIYAH JOURNAL FOR ENGINEERING SCIENCES}

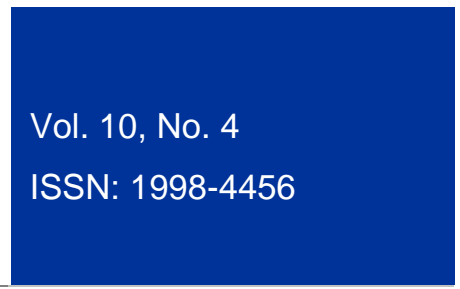

\subsection{RESULTS}

The results of tests are shown in figures (11-16), covering VSWR, return losses, and input resistance of each taper. From the figures of tests, it can be seen that the values of the pre mentioned parameters satisfying the standards values. Also the results show that there is no significant difference in the performance of the two tapers, although that the difference in length between them reaching an $8 \mathrm{~cm}$ as an extra length (i.e. there is smooth transition in cross section between the two ends of the long taper). Table 1 summarizes the results of the two tapers.

Table 1: results of the tests of two waveguide tapers.

\begin{tabular}{|l|l|l|l|}
\hline Taper No. & VSWR & Return losses & Input resistance \\
\hline $1(80 \mathrm{~mm})$ & 1.01 & $-46.1795 \mathrm{~dB}$ & $49.69 \Omega$ \\
\hline $2(160 \mathrm{~mm})$ & 1.011 & $-43.6314 \mathrm{~dB}$ & $49.44 \Omega$ \\
\hline
\end{tabular}

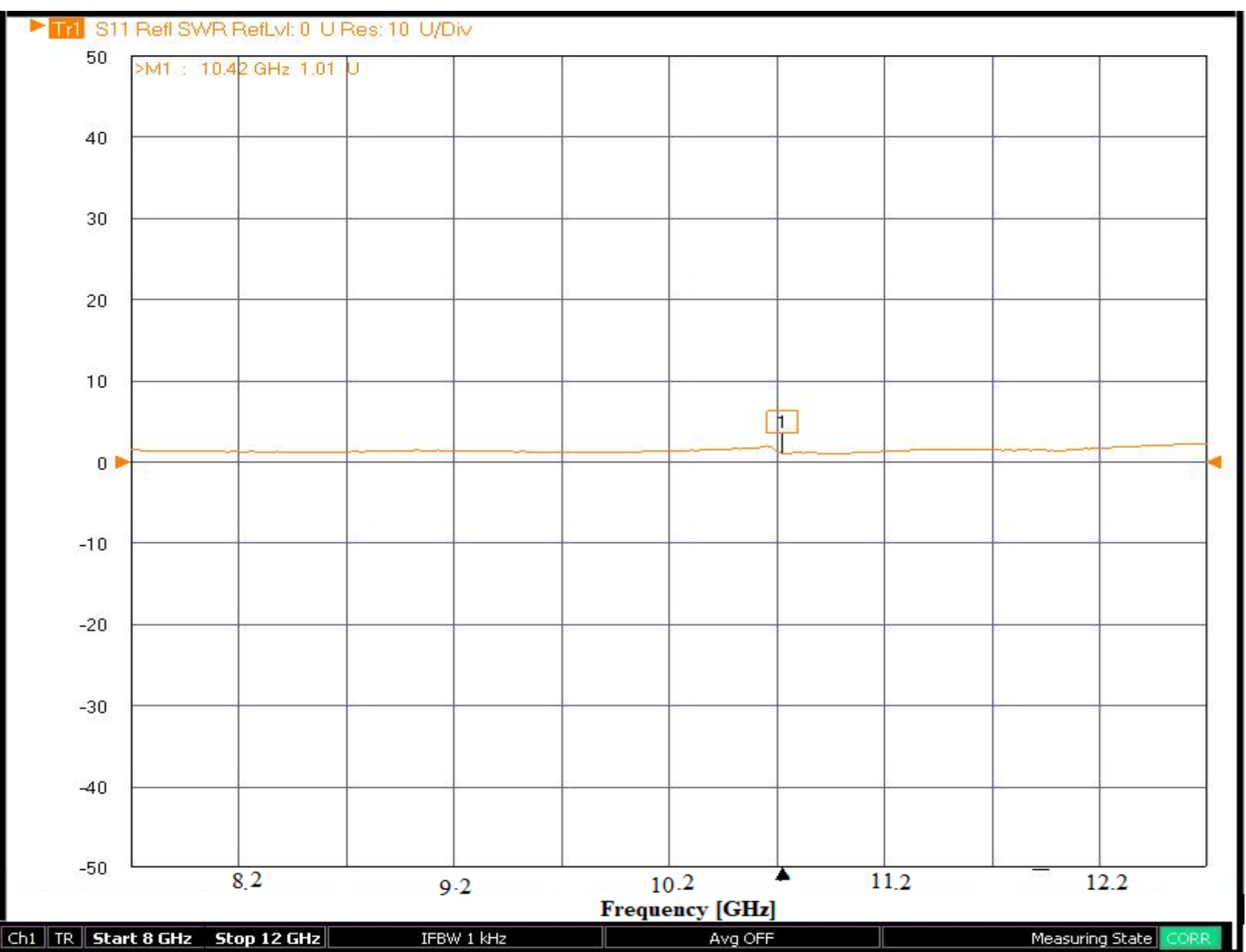

Figure 11: VSWR results of the short waveguide taper. 


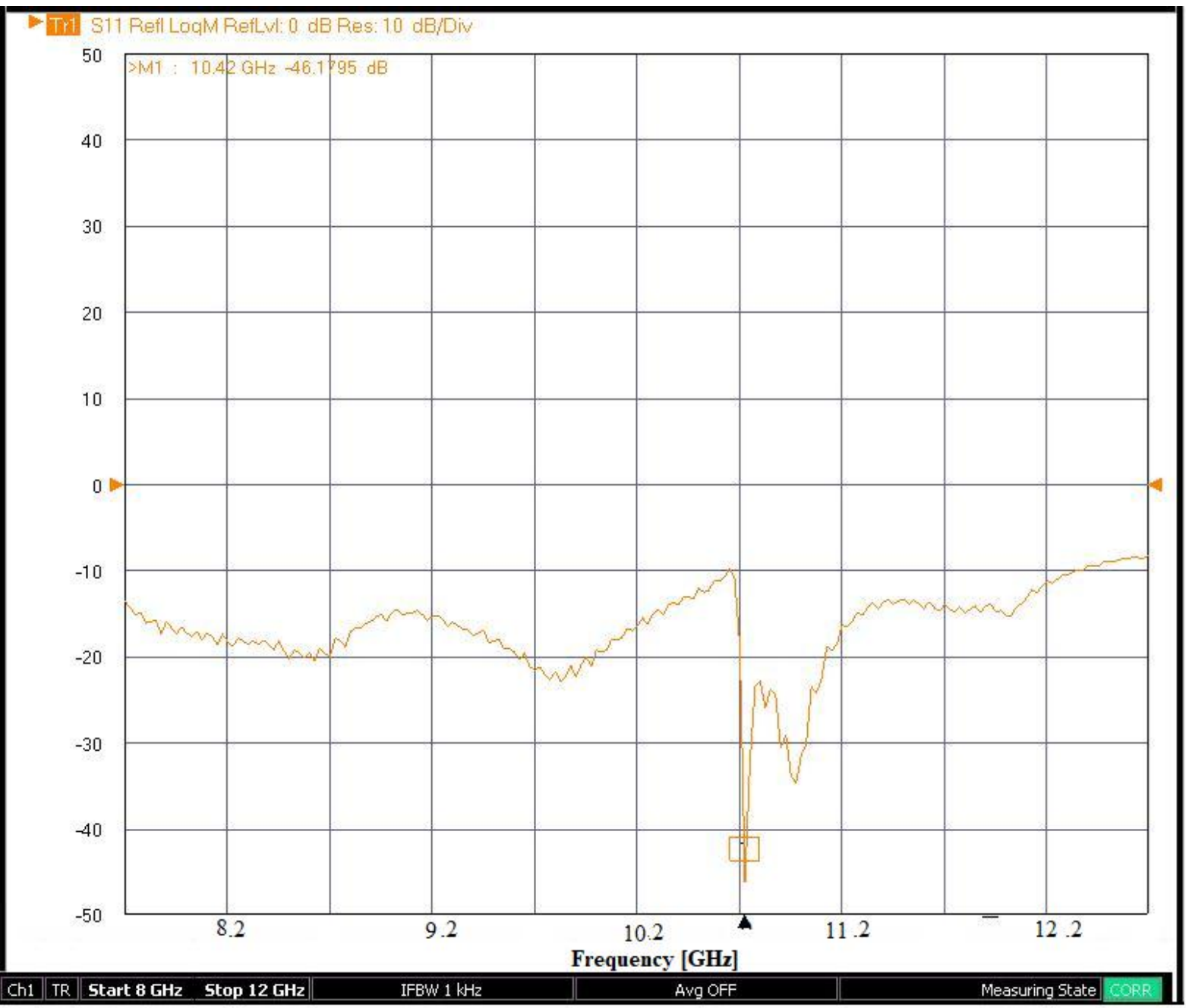

Figure 12: Reflection loss results of the short waveguide taper. 


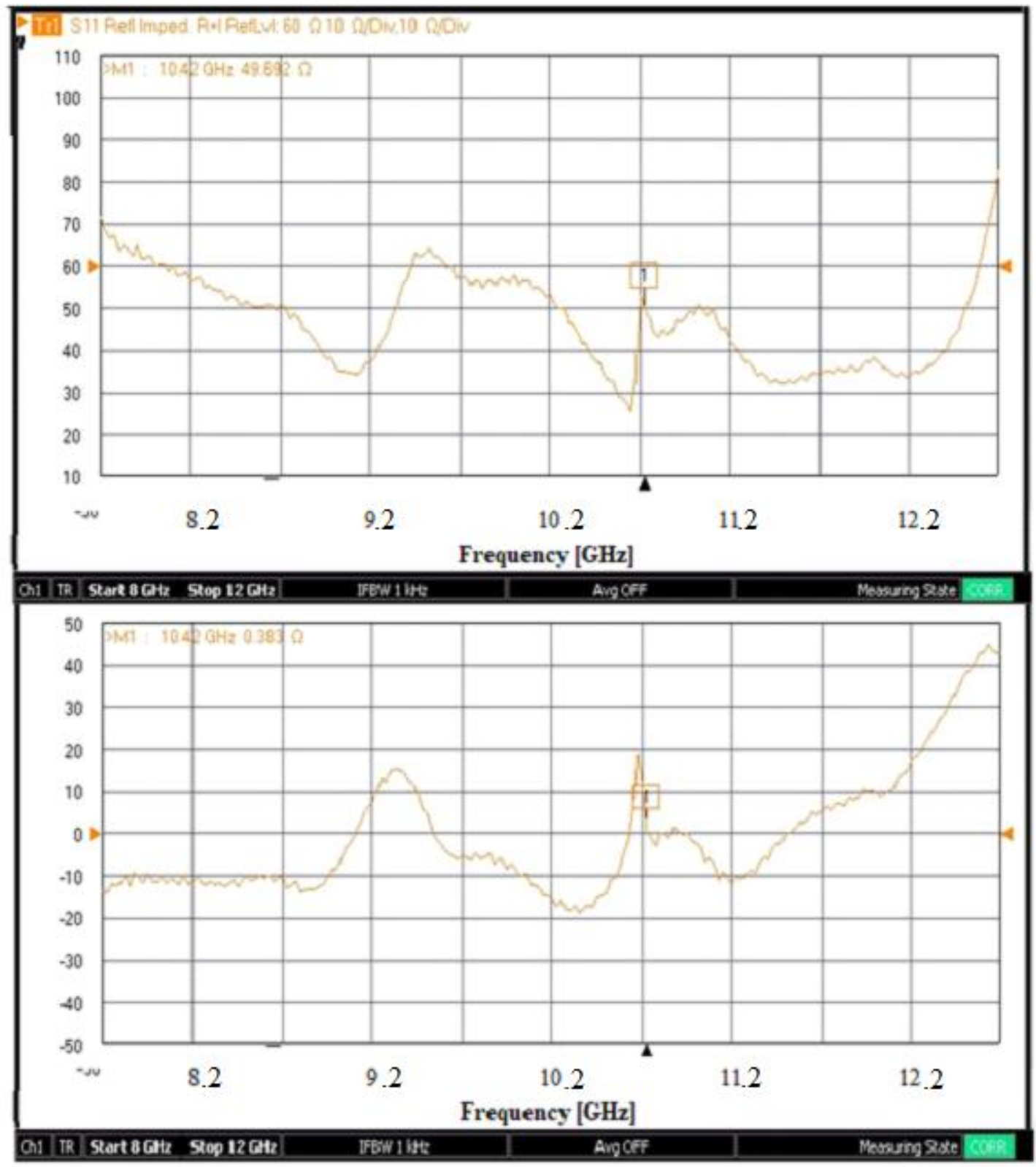

Figure 13: Z-parameter or input resistance result of the short waveguide taper. 


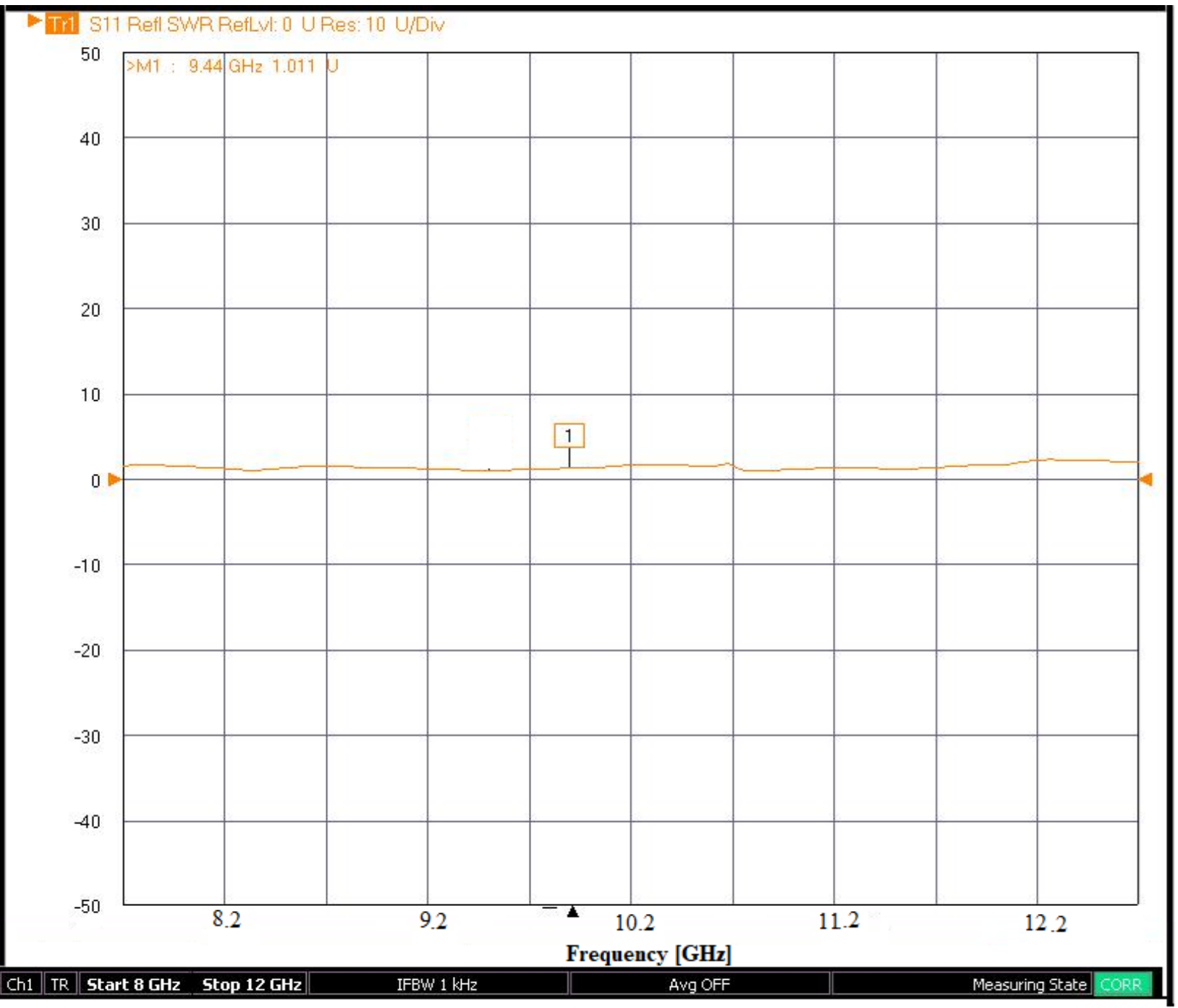

Figure 14: VSWR results of the long waveguide taper. 

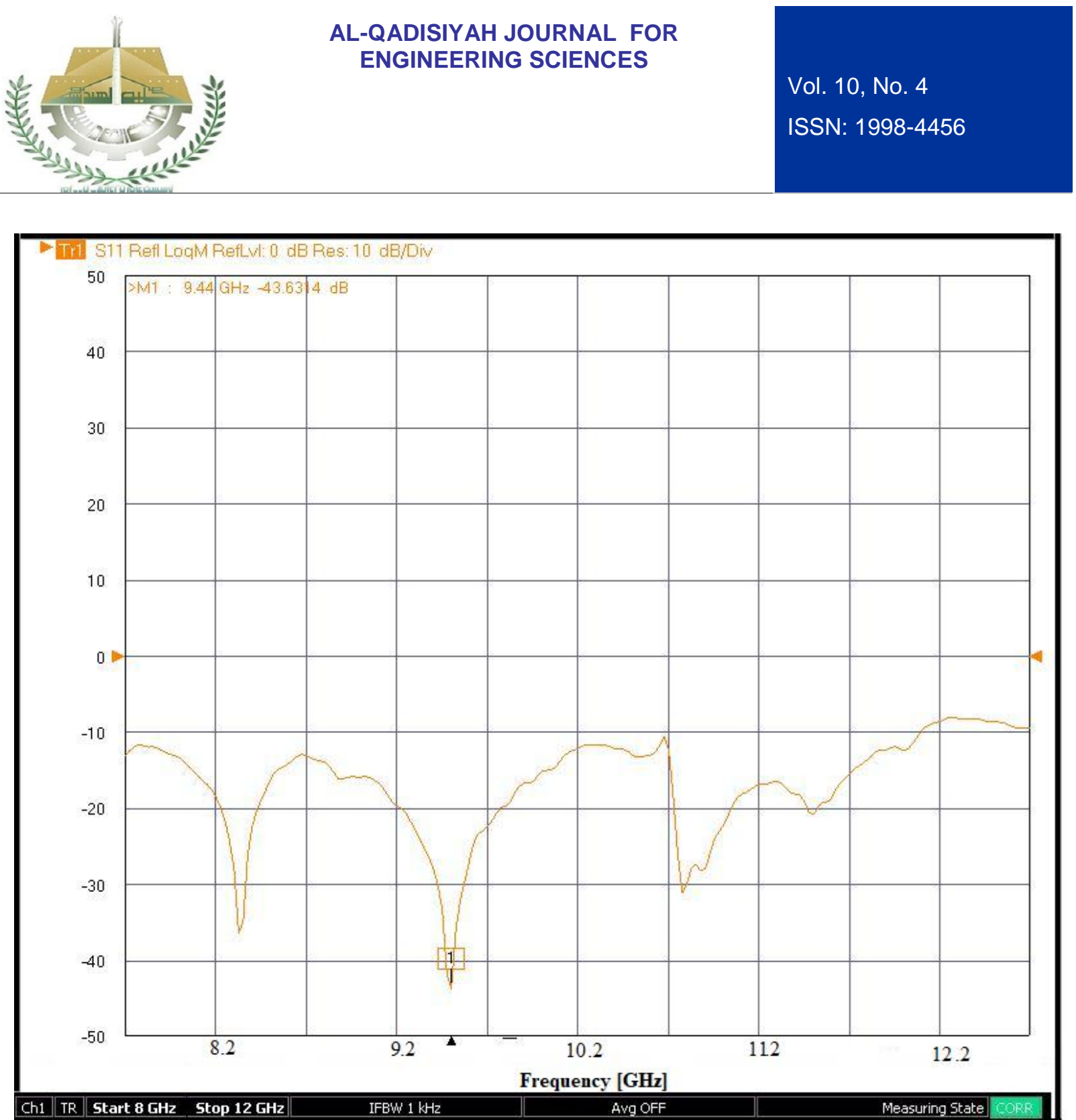

Figure 15: Reflection loss results of the long waveguide taper. 

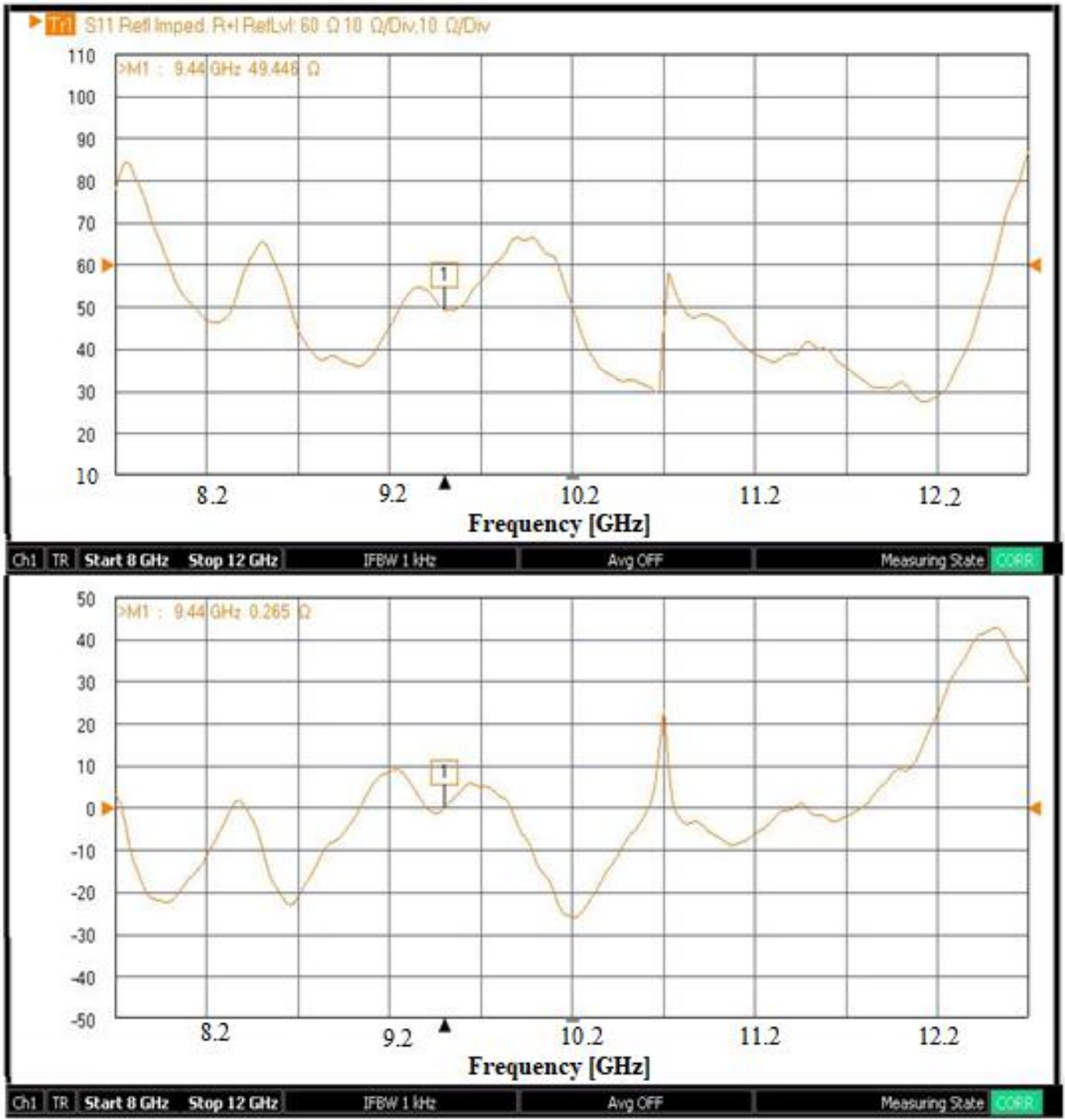

Figure 16: Z-parameter or input resistance result of the long waveguide taper.

\section{CONCLUSIONS}

From the results it can be conclude that the change of length of waveguide taper has no effect on the results and the performance of the long taper although that it has small flaring angle compare to the short one, so it can be use the tapers with any length according to the need of application.

\section{BIODATA}

- HASAN FAHAD KAZAAL is assistant professor at Electrical Engineering Department, Wasit University.

- HAIDER ALRIKABI is a lecturer at Electrical Engineering Department, Wasit University.

- MANSOUR S. FARHAN is assistant professor at Electrical Engineering Department, Wasit University. 


\section{REFERENCES}

1. Kamo B., Cakaj S., Koliçi V., Mulla E., " Simulation and Measurements of VSWR for MicrowaveCommunication Systems", Int. J. Communications, Network and System Sciences, issue 5, pp. 767-773, 2012.

2. Pasquali Microwave Systems company catalogue, http://www.pasquali-microwavesystems.com/.

3. SRB instruments company catalogue, http://azarel.com.sg/product/srb-catalogue/.

4. Trevor S. Bird, "Definition and Misuse of Return Loss", IEEE Antennas \& Propagation Magazine, Vol.51,issue.2, pp.166-167, April 2009.

5. Marcuvitz N., "Waveguide Handbook", Peter Peregrinus Ltd, 1986 edition. 